\title{
Evidence for temporally varying "sticky spots" at the base of Trapridge Glacier, Yukon Territory, Canada
}

\author{
Urs H. Fischer, ${ }^{1 *}$ Garry K. C. Clarke, ${ }^{1}$ Heinz Blatter ${ }^{2}$ \\ ${ }^{1}$ Department of Earth and Ocean Sciences, Cniversity of British Columbia, Vancowver, British Columbia V6 T 124, Canada \\ ${ }^{2}$ Geographisches Insitut, Eidgenössische Technische Hochschule, CH-8057 Zürich, Switzerland
}

\begin{abstract}
During the 1992 summer field season we installed arrays of "ploughmeters" and water-pressure transducers beneath Trapridge Glacier, Yukon Territory, Canada, to study hydromechanical coupling at the icc-bed interface. Diurnal signals recorded with two of these ploughmeters appear to corrclate with fluctuations in subglacial water pressurc. These diurnal variations can be explained by changes in basal resistance to sliding as mechanical conditions at the bed vary temporally in response to changes in the subglacial hydrological system. We propose that a lubricating water film, associated with high water pressures, promotcs glacier sliding, whereas low pressures causc increased basal drag resulting in "sticky" arcas. Using a thcorctical model, wc analyze the sliding motion of glacier ice over a flat surface having variable basal drag and show that a consistent explanation can be developed. Results from our model calculations provide strong support for the existence of time-varying sticky spots which are associated with fluctuations in subglacial water pressure.
\end{abstract}

\section{INTRODUCTION}

The flow of glaciers and ice streams is driven by gravity and opposed by resistive forces. Restraining forces acting at the bed result from some unknown combination of "sticky spots" at the ice bed interface, subglacial hydraulic conditions, topographic roughness and rhcological properties of the basal material. Sticky spots are localized regions of the bed where the basal shear stress is concentrated and which balance some or all of the applied driving stress (Alley, 1993).

Data from West Antarctica suggest the presence of sticky spots, which support high basal shear stress, surrounded by a generally well-lubricated, low-shear-strength bed. Forcebudgct calculations for ice flow at the Byrd Station strain network (Van der Veen and Whillans, 1989), where surface measurcments werc uscd to infer stresses at depth, showed that the basal drag is highly variable across the bed and concentrated at a few distinct points. 'These high-drag, slow-sliding sites are not always correlated with basal topographic highs, indicating that some process such as basal water drainage is involved in governing resistance at the bed. MacAyeal (1992) and MacAyeal and others (1995) used control methods to invert the obscrved surface velocity pattern of Ice Stream E for the distribution of subglacial friction. Irregularity of this inferred distribution suggests that ice is not undcrlain by a uniform laycr of deformable sediment and that increased basal friction is introduced by rigid bedrock or by variations in subglacial watcr pressurc. Allcy and others (1994) suggested that basal water has been diverted away from Ice Stream C, resulting in a disruption of

\footnotetext{
* Present address: Versuchsanstalt für Wasserbau, Hydrologie und Glaziologic, Eidgenössische Technische Hochschulc, CH-8092 Zürich, Switzerland.
}

the lubricating water film. They hypothesized that the ice stream has slowed and stopped due to the enhanced basal stress on a few sticky spots at the bed. Neighboring Ice Stream B flows rapidly $\left(400-800 \mathrm{~m}\right.$ a ${ }^{\prime}$ despitc its similarity to Ice Stream C in physical dimensions, accumulation, temperature (Shabtaie and others, 1987) and substrate properties (Rooncy and others, 1987; Atre and Bentlcy, 1993). Anandakrishnan and Alley (1994) suggest that sticky spots exist beneath Ice Stream B but rarely manifest themsclves in the force balance at the bed because they are better lubricatcd than those bencath Ice Strcam C. This conclusion is supported by observations that microseismic events are 20 times more abundant at the base of Ice Stream C than at the base of Ice Stream B Anandakrishnan and Bentley, 1993). The more frequent occurrence of microseismic events beneath Ice Stream $\mathrm{C}$ points to a difference in frictional character of sticky spots between the fast- and slow-moving ice streams.

The foregoing discussion highlights the reasons for current interest in the characteristics of subglacial sticky spots and the larger issuc of ice-bed coupling. Simultancous measurements of subglacial water pressure and ploughmeter response offer a unique approach to studying the mechanical and hydrological coupling betwcen a glacier and its bed. $\Lambda$ ploughmeter is essentially a $1.5 \mathrm{~m}$ long steel rod which is driven $\sim 0.1-0.2 \mathrm{~m}$ into subglacial sediment. The rod will bend elastically if the immersed tip is dragged through the sediment as the glacier slides forward (Fig. la). Strain gauges bondcd onto the rod register bending in two mutually orthogonal directions (Fig. lb). Detailed information on the construction, calibration, installation and thcory of this device is given in Fischer and Clarke (1994). Of relevance to the present study is the knowledge that, using the calibration, the bending moment as measured with the ploughmeter can be decomposed into a force applied to the 


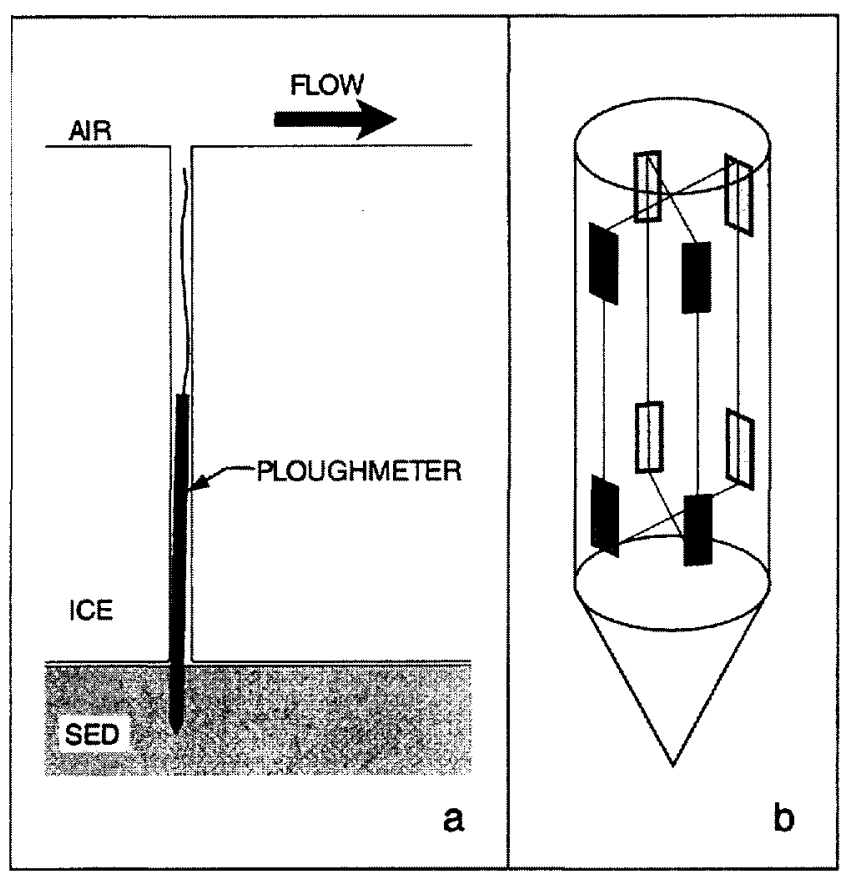

Fig. 1. (a) Shematic diagram of ploughmeter operalion. (b) Arrangeme'nt of strain gauges near the tip of the steel rod.

tip and the azimuth of this force with respect to internal coordinates of the device.

In this paper, we interpret data from two ploughmeters and a watcr-pressure sensor. To support this interpretation we develop a mathematical model to describe the sliding motion of glacier ice over a flat surface having spatially and temporally variablc drag. Solving for the velocity field of the ice immediately above the glacier bed, we calculate the behaviour of ploughmetcrs as they respond to temporal and spatial evolution of basal resistance. Comparison of our model results with field measurements yields evidence for temporal and spatial variations of sticky spots that are linked to changes in basal lubrication.

\section{FIELD OBSERVATIONS}

In July 1992, arrays of ploughmeters and subglacial waterpressure transducers wcre installed beneath Trapridge Glacier, Yukon Territory, Canada. Figure 2 shows 15 days of observations for ploughmeters 92PL02 and 92PL05. Data from subglacial water-pressure sensor $92 \mathrm{P} 06$ are also included and plotted along the same time axis. All three instruments are located within a circle of diameter $\sim 10 \mathrm{~m}$ in our main study region near the centre-line flow markers and about $600 \mathrm{~m}$ up-flow from the bulge. For a detailed description of the location and setting of the Trapridge Glacier study area see Clarke and Blake (1991). While many of the boreholes drillcd to the bed in this region of the glacier were not connected to the subglacial drainage system, obvious communication existed between the holes instrumented with the two ploughmeters and the pressure sensor and the basal hydrological system. The insertion sites of the ploughmeters 92PL02 and 92PL05 were approximately $10 \mathrm{~m}$ apart and the line joining the two sites was at an angle of $\sim 8^{\circ}$ from the dircction of glacier flow.

The records of both ploughmeters (Fig. $2 a-d$ ) display strong diurnal signals which appear to be correlated with large and rapid fluctuations in subglacial water pressure in-

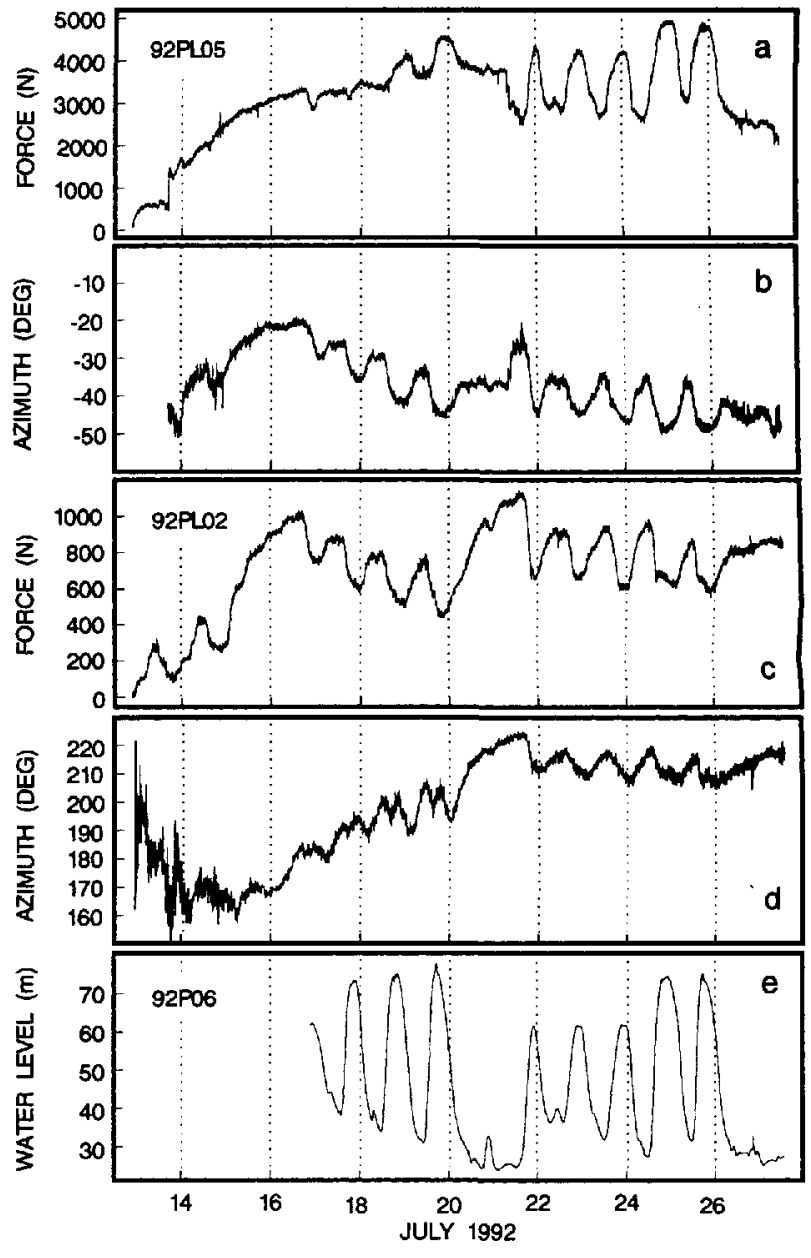

Fig. 2. Data from ploughmeters and pressure sensor. (a) Force record indicating force applied to the tip of ploughmeter 92PI02. (b) Azimuth of the forces with respect to the internal coordinates of 92PLO2. (c) Force record indicating force applied to the tip of ploughmeter 92PLO5. (d) Azimulh of the forces with respect to the internal coordinates of $92 P L 05$. (e) Subglacial water-pressure record from pressure sensor 92P06. Superflotation pressures correspond to a water level of more than about $63 \mathrm{~m}$.

dicatcd by sensor $92 \mathrm{P} 06$ (Fig. 2c). 'This correlation suggests that mechanical conditions at the bed vary temporally in response to changes in the basal hydrological system. However, there is a conspicuous difference in how the two ploughmeters respond to these changes in basal conditions. In the case of 92PL05 we see that variations in subglacial water pressure (Fig. 2e) are in phase with variations in the force responsc (Fig. 2a): high and low water pressures correspond to high and low forces, respectively. In fact, for the timc period starting 21 July, the two records look virtually identical, even to the finest detail. In contrast, peak water pressures appear to coincide with low forces experienced by 92 PL02 and vice versa (Fig. $2 \mathrm{c}$ and c). Thus, comparing Figure $2 \mathrm{a}$ and $\mathrm{c}$, we observe that the force record of 92PL 05 indicates a response that is $180^{\circ}$ out-of-phase with respect to that of 92PL02. At the same time, however, the azimuth records (Fig. 2b and d) indicate ploughmeter responses that are in phase with each other: for both ploughmeters the force angle appears to be rotating in the same sense back and forth by roughly $10^{\circ}$. This force-angle rotation might result from localized and temporally varying changes in the direction of glacier flow. 


\section{QUALITATIVE INTERPRETATION}

The correlation between the azimuth responses together with the strong anticorrelation between the force responses of the two ploughmeters could suggest that both ploughmeters are responding to the same external forcing. In the following analysis, we investigate the possibility that the mechanical behaviour of both ploughmeters is forced by variations in subglacial water pressure by a mechanism that operates differently for the two ploughmeters.

Fischer and Clarke (1994) showed that if subglacial sediment is treated as a layer of New tonian viscous fluid, then the force on a ploughmeter that is moving through it is linearly proportional to the effective fluid viscosity $\mu$, the translational velocity $v$ and a geometrical factor dependent on the shape and dimensions of the section of ploughmeter immersed in sediment (see Fischer and Clarke, 1994, equation (9)). The translational velocity $v$ is equal to the basal glacier sliding velocity $v_{\mathrm{b}}$ if subglacial sediment deformation is neglected. Thus, variations in the force response. of a ploughmeter could be due to any or all of the following: changes in the strength of basal material, changes in glacier sliding rate and changes in ploughmeter insertion depth into subglacial sediment. As in our previous analysis (Fischer and Clarke, 1994), we attribute all the variations in the force response to changes in basal sliding rate rather than changes in the insertion depth or strength of basal sediments.

Measurements of water pressure beneath Trapridge Glacier show that at any given time, basal water pressure is not uniform over the glacier bed (Stone and Clarke, 1996). In addition, large spatial pressure gradients can be observed between boreholes that are connected and those that are unconnected to the subglacial drainage system (Murray and Clarke, 1995). These observations suggest that we must treat mechanical conditions at the glacier bed on a local scale and that mechanical conditions should vary in response to localized changes in the subglacial hydrological system. In the following, we base our interpretation on the idea that a lubricating water film is associated with high subglacial water pressure, which effectively decouples the glacier from its bed and promotes sliding. In contrast, low pressures cause increased bottom drag. This idea follows from theory and observation that in a distributed subglacial drainage system, ice-bed separation by water increases with water pressure and that the glacier sliding velocity increases with ice-bed separation (Alley, 1996; and references therein). Significantly, measurements of bed deformation, bed shear strength, subglacial water pressure and surface speed at Storglaciären, Sweden (Iverson and others, 1995; Hooke and others, 1997), showed that the shear-strain rates of the bed decrease during periods of high water pressure and increased surface flow rate. Elevated water pressures were thercfore inferred to weaken the coupling of ice with the bed, allowing the glacier to move over the bed faster while deforming it less rapidly. This inference is substantiated by continuous measurements of basal sliding and subglacial water pressure at Trapridge Glacier (Blake and others, 1994; Fischer and Clarke, 1997) which indicated that there is substantial motion at the glacier sole during periods of rising water pressurc.

We consider a patch of glacier bed over which, at a starting time $t=t_{1}$, the basal water pressure is low. There is good mechanical coupling betwecn the glacier and the subglacial sediment because bed lubrication is poor. Basal resis- tance to sliding is higher than average, and little slip occurs between the bed and the overlying ice (Fig. 3a). At a later time $t=t_{2}$, subglacial water pressure has increased over the patch. Now the ice-bed interface is well lubricated and there is strong local decoupling of the glacier from its bed. Ice can slide more easily over this patch having lower than average bottom drag (Fig. 3b). $\Lambda$ s water pressure rises on the patch of bed under consideration, some of the shear traction exerted by the overlying ice will be redistributed onto surrounding regions.

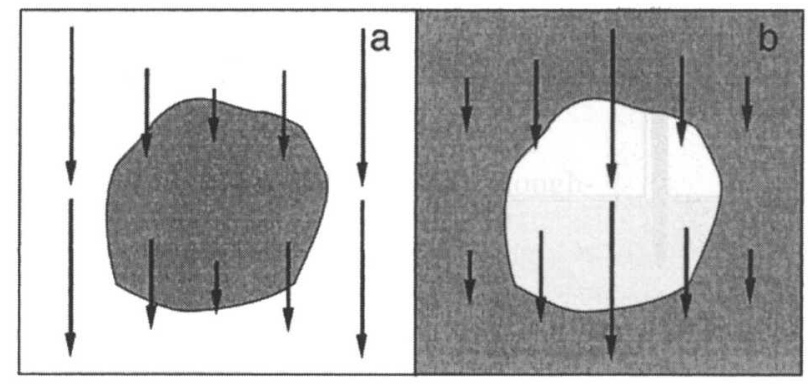

Fig. 3. Schematic diagram of temporal evolution of ice flow a.s a function of basal resistance. Shaded areas represent regions having higher than average bottom drag, while white areas indicate lower than average drag. (a) Low subglacial water pressure in centre of diagram. (b) High subglacial water pressure in centre of diagram.

While this interpretation ensures a roughly constant mean basal resistance averaged over the glacier bed, it also allows for spatially and temporally varying bottom drag as sticky spots are created and destroyed in response to fluctuations in subglacial water pressure. If a ploughmeter was positioned within the "sticky/slippery" patch in Figure 3 and another in the surrounding region, we see that the two ploughmeters would respond to the diurnal water-pressure forcing in ways that were $180^{\circ}$ out-of-phase with respect to cach other.

\section{QUANTITATIVE INTERPRETATION}

The foregoing qualitative explanation of water-pressure effects on bed coupling leads us to a mathematical treatment of ice flow over a bed having varying basal resistance to sliding. In this section we compute the velocity field for the ice immediately above the glacier bed as a function of bottom drag and explore how ploughmeters respond to the creation and destruction of sticky spots. In our model, we treat the bed as a hard, flat surface over which glacier sliding is controlled by spatially and temporally varying drag at the icebed interface. We note that we neglect the possible softening influence of high subglacial water pressures on the strength of the sedimentary bed. We make this assumption solely for the purpose of the model, but we appreciate that it is likely to be an oversimplification.

\section{Physical model and outline of analysis}

We analyze the flow of ice for a configuration in which the glacier is treated as a planar parallcl-sided slab of linear viscous rheology that rests on an incline. Coordinates are chosen with the $x$ axis along the ice-bed interface directed in the glacier flow direction and the $z$ axis normal to the bed and pointed positive upward. 
The problem is formulated as follows. For glacier ice treated as a linear viscous fluid with constant density $\rho_{\mathrm{I}}$ and constant viscosity $\eta$ and flowing at velocities slow cnough that inertial effects can be neglected, the ice-flow velocity field $\mathbf{v}$ satisfies

$$
\eta \nabla^{2} \mathbf{v}-\nabla p=-\rho_{\mathrm{I}} \mathbf{g}
$$

where $\eta$ is the dynamic viscosity of ice, $\mathbf{g}$ is the acceleration due to gravity and $p$ is the pressurc within the fluid. Ice is taken to be incompressible, thus

$$
\nabla \cdot \mathbf{v}=0
$$

Wc furthcr assume that the inclincd bed is a "flat" surface with a variable drag coefficient $f$ over which the ice moves with variable basal sliding velocity $\mathbf{v}_{\mathrm{b}}$. These assumptions contrast with those of standard glacier sliding theories where ice overlies a bedrock surface having a given topography and resistance arises from interaction of the ice with roughness elements. Here, the variability in the resistance to sliding is caused by patches of higher than average basal drag. The origin of the drag is the absence of a lubricating water film at the ice-bed interface during periods of low basal water pressures. Ice responds to the increased drag on the upstream sides of sticky patches by slowing down and diverging laterally at these points, thereby permitting the ice to move forward. Correspondingly, it speeds up and convcrges behind the sticky spots, in response to the reduced drag on the downstream sides. We assume that the basal shear traction vector $\mathbf{T}_{\mathrm{b}}$, is linearly proportional to the basal sliding rate

$$
\mathbf{T}_{\mathrm{b}}=f \mathbf{v}_{\mathrm{b}}
$$

where $f$ is a drag coefficicnt. Equation (3) is in direct analogy to the approach taken by MacAyeal (1992) in his calculation to infer basal friction from the observed surface velocity pattern of Ice Stream E.

\section{First-order perturbation}

We consider the drag coefficient $f$ to consist of a spatially constant background component $f^{0}$, which could be a function of time, upon which is superimposed a perturbation component $f^{\prime}$ which varies with time and position across the glacier bed. Hence,

$$
f(x, y, t)=f^{0}(t)+f^{\prime}(x, y, t)
$$

with the condition that $\left\langle f^{\prime}(x, y, t)\right\rangle=0$, where the angled brackets denote averaging over the glacier bed. With this assumption we note that the ice-flow velocity field is also the sum of a slowly varying background component and a more rapidly varying perturbation component, i.e.

$$
\mathbf{v}(x, y, z, t)=\mathbf{v}^{0}(z, t)+\mathbf{v}^{\prime}(x, y, z, t) .
$$

Similarly, we can write for the basal sliding velocity $\mathbf{v}_{\mathrm{b}}$ that

$$
\mathbf{v}_{\mathrm{b}}(x, y, t)=\mathbf{v}_{\mathrm{b}}^{0}(t)+\mathbf{v}_{\mathrm{b}}^{\prime}(x, y, t),
$$

where $\quad \mathbf{v}_{\mathrm{b}}(x, y, t)=\mathbf{v}(x, y, 0, t), \mathbf{v}_{\mathrm{b}}^{0}(t)=\mathbf{v}^{0}(0, t) \quad$ and $\mathbf{v}_{\mathrm{b}}^{\prime}(x, y, t)=\mathbf{v}^{\prime}(x, y, 0, t)$. Substituting Equations (4) and
(6) into Equation (3) and ignoring higher-order perturbation terms yiclds

$$
\begin{aligned}
\mathbf{T}_{\mathrm{b}}(x, y, t)= & {\left[f^{0}(t)+f^{\prime}(x, y, t)\right]\left[\mathbf{v}_{\mathrm{b}}^{0}(t)+\mathbf{v}_{\mathrm{b}}^{\prime}(x, y, t)\right] } \\
= & f^{0}(t) \mathbf{v}_{\mathrm{b}}^{0}(t)+\mathbf{v}_{\mathrm{b}}^{0}(t) f^{\prime}(x, y, t) \\
& +f^{0}(t) \mathbf{v}_{\mathrm{b}}^{\prime}(x, y, t)+\ldots
\end{aligned}
$$

We can split Equation (7) into two equations, one that represents linear background sliding,

$$
\mathbf{T}_{\mathrm{b}}^{0}=f^{0}(t) \mathbf{v}_{\mathrm{b}}^{0}(t)
$$

and one that describes linear sliding duc to the perturbation effects,

$$
\mathbf{T}_{b}^{\prime}(x, y, t)=f^{\prime}(x, y, t) \mathbf{v}_{\mathrm{b}}^{0}(t)+f^{0}(t) \mathbf{v}_{\mathrm{b}}^{\prime}(x, y, t) .
$$

Note that in Equation (7), $\mathbf{T}_{\mathrm{b}}$ varies with both time and space but its variations are constrained by the fact that the average over the glacier bed $\left\langle\mathbf{T}_{\mathrm{b}}(x, y, t)\right\rangle=\mathbf{T}_{\mathrm{b}}^{0}$. Likewise in Equation (9) the spatial average of the perturbation $\left\langle\mathbf{T}_{\mathrm{b}}^{\prime}(x, y, t)\right\rangle$ vanishes. Equation (4) further implies that the pressure also consists of a temporally and spatially varying perturbation component superimposed onto a time-varying background component, i.e.

$$
p(x, y, z, t)=p^{0}(z, t)+p^{\prime}(x, y, z, t) .
$$

Finally we make the simplifying assumption that the coordinate system is aligned with the background sliding component which is oriented along the positive $x$ axis; thus $\mathbf{v}_{\mathrm{b}}^{0}(t)=v_{\mathrm{b} x}^{0}(t) \mathbf{i}, v_{\mathrm{b} y}^{0}(t)=0$ and $\mathbf{v}_{\mathrm{b}}^{\prime}(x, y, t)=v_{\mathrm{b} x}^{\prime}(x, y, t) \mathbf{i}+$ $v_{\mathrm{by}}^{\prime}(x, y, t) \mathbf{j}$, where $\mathbf{i}$ and $\mathbf{j}$ are unit vectors.

\section{Variations in sliding due to perturbation effects}

Substitution of Equations (5) and (10) into Equation (1) gives

$$
\eta \nabla^{2}\left(\mathbf{v}^{0}+\mathbf{v}^{\prime}\right)-\nabla\left(p^{0}+p^{\prime}\right)=-\rho_{\mathrm{I}} \mathbf{g} .
$$

The linearity of Equation (11) results in the perturbation ficlds being independent of and additional to the background distribution. Hence, the perturbation equations that command attention are the following:

$$
\eta \nabla^{2} \mathbf{v}^{\prime}(x, y, z, t)-\nabla p^{\prime}(x, y, z, t)=0
$$

and

$$
\nabla^{2} p^{\prime}=0
$$

Equation (13) is equivalent to the incompressibility equation and follows from taking the divergence of Equation (12) and imposing the condition $\nabla \cdot \mathbf{v}^{\prime}=0$ (Equation (2)). The gravitational body force does not appear in Equation (12) because perturbation cffects are not driven by gravity.

We follow the treatment used by Kamb (1970) on regelation sliding and solve Equations (12) and (13) by the Fourieranalytical method. Fouricr transformation of Equation (13) with respect to $x$ and $y$ gives

$$
\frac{\mathrm{d}^{2}}{\mathrm{~d} z^{2}} \widetilde{P}^{\prime}\left(k_{x}, k_{y}, z, t\right)-\left(k_{x}^{2}+k_{y}^{2}\right) \widetilde{P}^{\prime}\left(k_{x}, k_{y}, z, t\right)=0 .
$$

If one assumes that the surface is very far from the bed then the standard solution of Equation (14) is

$$
\widetilde{P}^{\prime}\left(k_{x}, k_{y}, z, t\right)=\widetilde{P}^{\prime}\left(k_{x}, k_{y}, 0, t\right) \exp \left[-\left(k_{x}^{2}+k_{y}^{2}\right)^{\frac{1}{2}} z\right] .
$$

The boundary conditions that are satisfied by Equation (15) are that the pressure perturbations at the bed (where $z=0$ ) are described by $\widetilde{P}^{\prime}\left(k_{x}, k_{y}, 0, t\right)$ and that the perturbations vanish as $z$ becomes large. 
In a similar fashion the three components of the Fouriertransformed version of Equation (12) can be written as

$$
\begin{aligned}
& \eta \frac{\mathrm{d}^{2}}{\mathrm{~d} z^{2}} \widetilde{V_{x}^{\prime}}\left(k_{x}, k_{y}, z, t\right)-\eta k^{2}{\widetilde{V_{x}}}_{x}\left(k_{x}, k_{y}, z, t\right) \\
& -i k_{x} \widetilde{P}^{\prime}\left(k_{x}, k_{y}, 0, t\right) \exp (-k z)=0 \\
& \eta \frac{\mathrm{d}^{2}}{\mathrm{~d} z^{2}} \tilde{V}_{y}^{\prime}\left(k_{x}, k_{y}, z, t\right)-\eta k^{2} \tilde{V}_{y}^{\prime}\left(k_{x}, k_{y}, z, t\right) \\
& -i k_{y} \widetilde{P}^{\prime}\left(k_{x}, k_{y}, 0, t\right) \exp (-k z)=0 \\
& \eta \frac{\mathrm{d}^{2}}{\mathrm{~d} z^{2}} \tilde{V}_{z}^{\prime}\left(k_{x}, k_{y}, z, t\right)-\eta k^{2} \widetilde{V}_{z}^{\prime}\left(k_{x}, k_{y}, z, t\right) \\
& +k \widetilde{P}^{\prime}\left(k_{x}, k_{y}, 0, t\right) \exp (-k z)=0,
\end{aligned}
$$

where $k^{2}=k_{x}^{2}+k_{y}^{2}$. Equations $(16 \mathrm{a}-\mathrm{c})$ have the general form

$$
\frac{\mathrm{d}^{2} F}{\mathrm{~d} z^{2}}-k^{2} F=A \exp (-k z)
$$

and the general solution

$$
F(z)=-\frac{A z}{2 k} \exp (-k z)+B \exp (-k z) .
$$

Applying Equation (18) to the solution of Equations (16a-c) gives the solutions

$$
\begin{aligned}
\widetilde{V}_{x}^{\prime}\left(k_{x}, k_{y}, z, t\right)= & {\left[-\frac{i k_{x}}{2 \eta k} \widetilde{P}^{\prime}\left(k_{x}, k_{y}, 0, t\right) z+\widetilde{V}_{x}^{\prime}\left(k_{x}, k_{y}, 0, t\right)\right] } \\
& \exp (-k z) \\
\widetilde{V}_{y}^{\prime}\left(k_{x}, k_{y}, z, t\right)= & {\left[-\frac{i k_{y}}{2 \eta k} \widetilde{P}^{\prime}\left(k_{x}, k_{y}, 0, t\right) z+\widetilde{V}_{y}^{\prime}\left(k_{x}, k_{y}, 0, t\right)\right] } \\
& \exp (-k z) \\
\tilde{V}_{z}^{\prime}\left(k_{x}, k_{y}, z, t\right)= & \frac{1}{2 \eta} \widetilde{P}^{\prime}\left(k_{x}, k_{y}, 0, t\right) z \exp (-k z) .
\end{aligned}
$$
that

The incompressibility condition (Equation (2)) rcquires

$$
\begin{aligned}
+i k_{x} \widetilde{V}_{x}^{\prime}\left(k_{x}, k_{y}, z, t\right) & +i k_{y} \widetilde{V}_{y}^{\prime}\left(k_{x}, k_{y}, z, t\right) \\
& +\frac{\mathrm{d}}{\mathrm{d} z} \widetilde{V}_{z}^{\prime}\left(k_{x}, k_{y}, z, t\right)=0,
\end{aligned}
$$

and applying this condition imposes restrictions on Equations $\left(19 a^{-} \mathrm{c}\right)$. Performing this step gives

$$
\begin{aligned}
\widetilde{P}^{\prime}\left(k_{x}, k_{y}, 0, t\right)= & -2 i \eta k_{x} \widetilde{V_{x}^{\prime}}\left(k_{x}, k_{y}, 0, t\right) \\
& -2 i \eta k_{y} \widetilde{V_{y}^{\prime}}\left(k_{x}, k_{y}, 0, t\right) .
\end{aligned}
$$

Equation (21) can be applied to the velocity solutions $(19 \mathrm{a}-\mathrm{c})$ to obtain

$$
\begin{aligned}
\widetilde{V}_{x}^{\prime}\left(k_{x}, k_{y}, z, t\right)= & -\frac{k_{x} z}{k}\left[k_{x} \widetilde{V}_{x}^{\prime}\left(k_{x}, k_{y}, 0, t\right)\right. \\
& \left.+k_{y} \widetilde{V_{y}^{\prime}}\left(k_{x}, k_{y}, 0, t\right)\right] \exp (-k z) \\
& +\widetilde{V_{x}^{\prime}}\left(k_{x}, k_{y}, 0, t\right) \exp (-k z) \\
\widetilde{V}_{y}^{\prime}\left(k_{x}, k_{y}, z, t\right)= & -\frac{k_{y} z}{k}\left[k_{x} \widetilde{V}_{x}^{\prime}\left(k_{x}, k_{y}, 0, t\right)\right. \\
& \left.+k_{y} \widetilde{V}_{y}^{\prime}\left(k_{x}, k_{y}, 0, t\right)\right] \exp (-k z) \\
& +\widetilde{V_{y}^{\prime}}\left(k_{x}, k_{y}, 0, t\right) \exp (-k z) \\
\widetilde{V}_{z}^{\prime}\left(k_{x}, k_{y}, z, t\right)= & -i z\left[k_{x} \widetilde{V}_{x}^{\prime}\left(k_{x}, k_{y}, 0, t\right)\right. \\
& \left.+k_{y} \widetilde{V}_{y}^{\prime}\left(k_{x}, k_{y}, 0, t\right)\right] \exp (-k z) .
\end{aligned}
$$

Now we relate perturbations in basal stress to those of basal velocity. From the constitutive equation for a linear viscous fluid

$$
\sigma_{i j}=2 \eta \dot{\epsilon}_{i j}-p \delta_{i j}
$$

where $\sigma_{i j}$ is the stress tensor, $\dot{\epsilon}_{i j}$ is the strain-rate tensor and $\delta_{i j}$ is the Kronecker delta, it follows that

$$
\begin{aligned}
& \sigma_{x z}=\eta \frac{\partial v_{x}}{\partial z} \\
& \sigma_{y z}=\eta \frac{\partial v_{y}}{\partial z}
\end{aligned}
$$

with similar equations applying to the perturbation stress and velocity fields. In Fourier-transformed variables the equations of interest are

$$
\begin{aligned}
& \tilde{\sigma}_{x z}^{\prime}\left(k_{x}, k_{y}, z, t\right)=\eta \frac{\mathrm{d} \widetilde{V}_{x}^{\prime}\left(k_{x}, k_{y}, z, t\right)}{\mathrm{d} z} \\
& \tilde{\sigma}_{y z}^{\prime}\left(k_{x}, k_{y}, z, t\right)=\eta \frac{\mathrm{d} \tilde{V}_{y}^{\prime}\left(k_{x}, k_{y}, z, t\right)}{\mathrm{d} z} .
\end{aligned}
$$

From Equations (22a) and (22b) it follows that

$$
\begin{aligned}
& \frac{\mathrm{d}}{\mathrm{d} z} \widetilde{V}_{x}^{\prime}\left(k_{x}, k_{y}, z, t\right) \\
& \quad=\left(-\frac{k_{x}^{2}}{k}+k_{x}^{2} z-k\right) \widetilde{V}_{x}^{\prime}\left(k_{x}, k_{y}, 0, t\right) \exp (-k z) \\
& \quad+\left(-\frac{k_{x} k_{y}}{k}+k_{x} k_{y} z\right) \widetilde{V}_{y}^{\prime}\left(k_{x}, k_{y}, 0, t\right) \exp (-k z) \\
& \frac{\mathrm{d}}{\mathrm{d} z} \widetilde{V}_{y}^{\prime}\left(k_{x}, k_{y}, z, t\right) \\
& \quad=\left(-\frac{k_{x} k_{y}}{k}+k_{x} k_{y} z\right) \widetilde{V}_{x}^{\prime}\left(k_{x}, k_{y}, 0, t\right) \exp (-k z) \\
& \quad+\left(-\frac{k_{y}^{2}}{k}+k_{y}^{2} z-k\right) \widetilde{V}_{y}^{\prime}\left(k_{x}, k_{y}, 0, t\right) \exp (-k z) .
\end{aligned}
$$

At the $z=0$ boundary the friction law (Equation (9)) gives the following relationships:

$$
\begin{aligned}
& \eta \frac{\mathrm{d}}{\mathrm{d} z} \tilde{V}_{x}^{\prime}\left(k_{x}, k_{y}, 0, t\right) \\
& =v_{\mathrm{b} x}^{0}(l) \tilde{f}^{\prime}\left(k_{x}, k_{y}, t\right)+f^{0}(t) \tilde{V}_{x}^{\prime}\left(k_{x}, k_{y}, 0, t\right) \\
& \eta \frac{\mathrm{d}}{\mathrm{d} z} \dot{V}_{y}^{\prime}\left(k_{x}, k_{y}, 0, t\right)=f^{0}(t) \tilde{V}_{y}^{\prime}\left(k_{x}, k_{y}, 0, t\right) \text {. }
\end{aligned}
$$

In Equation (27b) we assumed that the coordinate system has been chosen such that $v_{\mathrm{b} y}^{0}(t) \equiv 0$. Combining Equations (26) and (27) we find that

$$
\begin{aligned}
&-\left[\eta\left(k_{x}^{2}=k^{2}\right)\right.\left.+k f^{0}(t)\right] \tilde{V}_{x}^{\prime}\left(k_{x}, k_{y}, 0, t\right) \\
&-\eta k_{x} k_{y} \widetilde{V}_{y}^{\prime}\left(k_{x}, k_{y}, 0, t\right) \\
&=v_{\mathrm{b} x}^{0}(t) k \tilde{f}^{\prime}\left(k_{x}, k_{y}, t\right) \\
&-\eta k_{x} k_{y} \widetilde{V}_{x}^{\prime}\left(k_{x}, k_{y}, 0, t\right)-\left[\eta\left(k_{y}^{2}+k^{2}\right)+k f^{0}(t)\right] \\
& \widetilde{V}_{y}^{\prime}\left(k_{x}, k_{y}, 0, t\right)=0 .
\end{aligned}
$$

Note that Equations (28a) and (28b) constitute a pair of linear equations in the unknowns $\tilde{V}_{x}^{\prime}\left(k_{x}, k_{y}, 0, t\right)$ and $\widetilde{V}_{y}^{\prime}\left(k_{x}, k_{y}, 0, t\right)$. From Equation $(28 \mathrm{~b})$ it is apparent that the $y$ component of the perturbation velocity field is

$$
\tilde{V}_{y}^{\prime}\left(k_{x}, k_{y}, 0, t\right)=-\frac{\eta k_{x} k_{y}}{\eta\left(k_{y}^{2}+k^{2}\right)+k f^{0}(t)} \widetilde{V_{x}^{\prime}}\left(k_{x}, k_{y}, 0, t\right) \text {. }
$$

Substituting Equation (29) into Equation (28a) and solving 
for $\tilde{V}_{x}^{\prime}\left(k_{x}, k_{y}, 0, t\right)$ gives the $x$ component of the perturbation velocity field

$$
\begin{aligned}
& \hat{V}_{x}^{\prime}\left(k_{x}, k_{y}, 0, t\right) \\
& =\frac{\left[\eta\left(k_{y}^{2}+k^{2}\right)+k f^{0}(t)\right] v_{x}^{0}(t) k \tilde{f}^{\prime}\left(k_{x}, k_{y}, t\right)}{\eta^{2} k_{x}^{2} k_{y}^{2}-\left[\eta\left(k_{x}^{2}+k^{2}\right)+k f^{0}(t)\right]\left[\eta\left(k_{y}^{2}+k^{2}\right)+k f^{0}(t)\right]} .
\end{aligned}
$$

\section{Description of drag-coefficient surface}

Consider a part of the bed of arca $A$, assumed to be rectangular of dimensions $L_{x}$ and $L_{y}$ in the $x$ and $y$ directions. Within this area we define a drag-coefficient surface $f(x, y, t)$ to consist of a spatially constant background component $f^{0}(t)$ superimposed by a spatially and temporally variable perturbation component $f^{\prime}(x, y, t)$ with the condition that

$$
\left\langle f^{\prime}(x, y, t)\right\rangle=0
$$

where the angled brackets denote averaging over $A$ (Fig. 4). The perturbation drag-coefficient surface is described by patches with dimensions $w_{x}$ and $w_{y}$ in the $x$ and $y$ directions, respectively, that are centred on coordinates $(\bar{x}, y)$ and have higher than average $\operatorname{drag} f_{-}^{\prime}$, while a lower than average drag $f_{-}^{\prime}$ has been assigned to the rest of the surface. The magnitude of $f_{-}^{\prime}$ cannot excecd $f^{0}(t)$ since a negative drag coefficient $f(x, y, t)$ is not physically meaningful. In addition, the magnitudes of $f_{+}^{\prime}$ and $f_{-}^{\prime}$ are generally not cqual and depend on the areal fraction that is covered by sticky patches (e.g. small patches with large positive $f_{+}^{\prime}$ values are accompanicd by small negative $f_{-}^{\prime}$ values for the rest of the surface).

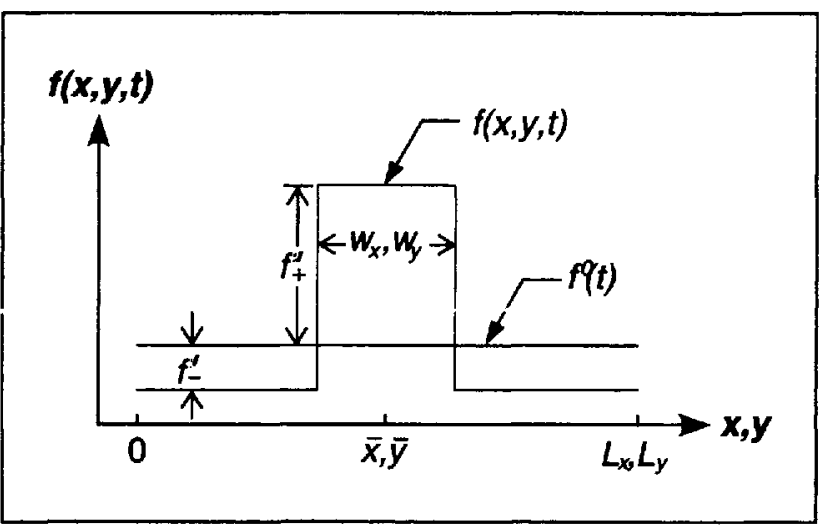

Fig. 4. Diagram of drag-coefficient surface $f(x, y, t)$ defined over a rectangular region of area $A=L_{x} L_{y}$.

We take the drag-coefficient surfacc $f(x, y, t)$ to be pcriodically repeated over the entire $x-y$ plane, so that the bed, of assumed infinite extent, consists of a checkerboard of identical arcas $A$, across which the ice slides in the $x$ direction. While a real glacier bed is not periodic in this strict sensc, our assumption of repeat distances $L_{x}$ and $L_{y}$ simplifies calculation of the Fourier transform of the perturbation drag-coefficient surfacc.

\section{Model results}

In Table 1 we have listed the modcl parameters that were used to obtain the calculated solutions. Glen's flow law com-

\begin{tabular}{|c|c|c|c|}
\hline Parameter & Symbol & Value & lnits \\
\hline Effective dynamic ice viscosity & $\eta$ & $3.0 \times 10^{12}$ & Pas \\
\hline Background basal sliding velocity & $v_{\mathrm{b} x}^{0}$ & 40 & $\mathrm{mman}^{\prime}$ \\
\hline Background drag coefficient & $f^{0}$ & $1.66 \times 10^{11}$ & Pas sm \\
\hline Peak perturbation drag coefficient & $f_{+}^{\prime}$ & $3.17 \times 10^{11}$ & Pasm ${ }^{1}$ \\
\hline Length of arca $A$ in $x$ direction & $L_{x}$ & 20 & $\mathrm{~m}$ \\
\hline Length of area $A$ in $y$ direction & $L_{y}$ & 20 & $\mathrm{~m}$ \\
\hline Number of gridpoints in $x$ direction & $N_{x}$ & 32 & \\
\hline Number of gridpoints in $y$ direction & $N_{y}$ & 32 & \\
\hline Size of sticky paiches in $x$ dirertion & $w_{x}$ & 10.0 & $\mathrm{~m}$ \\
\hline Size of sticky patches in $y$ direction & $w_{y}$ & 3.75 & $m$ \\
\hline
\end{tabular}
bined with Equation (23) yields an estimate of the effective
Table 1. Parameters for "sticky spot" model

dynamic viscosity of ice

$$
\eta=\frac{1}{2 B \tau_{\mathrm{b}}^{n-1}},
$$

where $\tau_{\mathrm{b}}=\sqrt{\mathbf{T}_{\mathrm{b}} \cdot \mathbf{T}_{\mathrm{b}}}$ is the basal shear-stress magnitude. Using a flow-law parameter for temperate ice $B=$ $6.8 \times 10^{-15} \mathrm{~s}^{-1} \mathrm{kPa}^{-3}, n=3$ (Paterson, 1994, p.97)) and a mean basal shear stress of $\tau_{\mathrm{b}}=77 \mathrm{kPa}$ (bascd on an icc thickness of $72 \mathrm{~m}$ and a surface slope of $7 \%$, we calculated a Trapridge Glacier ice viscosity of $\eta=1.24 \times 10^{13} \mathrm{~Pa}$ s. Fnhanced creep due to stress concentrations ncar the bed is likely to soften this basal icc; thus, we reduce the value of icc viscosity by one order of magnitude and, somewhat arbitrarily, take $\eta=3.0 \times 10^{12} \mathrm{Pas}$ in our model calculations (Table 1). With an average basal sliding velocity for Trapridge Glacier of $v_{\mathrm{b} x}^{0}=40 \mathrm{~mm} \mathrm{~d}^{-1}$ (Blake and others, 1994) substituted into Equation (8) the resulting background drag cocfficient is $f^{0}=1.66 \times 10^{11} \mathrm{~Pa} \mathrm{~s} \mathrm{~m}^{-1}$ (Table 1).

For the model calculations discussed in this section, area $A$ has becn divided into a $32 \times 32$ grid. Following the description in the previous section, positive $f_{+}^{\prime}$ or negative $f_{-}^{\prime}$ values were then assigned to every gridpoint. The frictional perturbation $f^{\prime}(x, y, t)$ was Fourier-transformed using a two-dimcnsional fast-Fouricr-transform algorithm (Press and others, 1992, p.515) to obtain $\tilde{f}^{\prime}\left(k_{x}, k_{y}, t\right)$ and subsequently substituted into Equation (30) to find the sliding velocity perturbation $\widetilde{V}_{x}^{\prime}\left(k_{x}, k_{y}, 0, t\right)$. The sliding perturbation $\widetilde{V}_{y}^{\prime}\left(k_{x}, k_{y}, 0, t\right)$ follows immediately from Equation (29). Inverse Fourier transformation of the perturbation velocity field $\widetilde{\mathbf{V}}^{\prime}\left(k_{x}, k_{y}, 0, t\right)$ yields $\mathbf{v}^{\prime}(x, y, 0, t)$.

The drag-coefficient surface shown in Figurc 5 a consists of rectangular patches having higher than average drag centred on gridpoint $(17,17)$ and the four corners of area $A$, while the remainder of $A$ has lower than average drag. For a peak perturbation drag coefficient $f_{+}^{\prime}=3.47 \times 10^{11} \mathrm{Pas} \mathrm{m}^{1}$ for the patches having dimensions $w_{x}=16$ and $w_{y}=6$ gridpoints, we obtained $f_{-}^{t}=-0.8 \times 10^{11} \mathrm{Pasm}^{-1}$ for the rest of the surface from Equation (31). The resulting flow velocity field (Fig. 5b) shows how the ice is being slowed down and diverted around the high-resistance patch in the centre of arca $A$. Here and in subsequent plots of flow velocity fields, the background sliding velocity $v_{\mathrm{b} x}^{0}$ has been added to the perturbation velocity field (note that $v_{\mathrm{b} y}^{0}=0$ ). In Figure $5 c$, the drag-coefficient surface consists of a rcsistance low in the centre of area $A$ with patches of higher than average drag located on the midpoints of the sides of the square area. Now the ice is allowed to accelerate and be channelled toward this low-resistance patch (Fig. 5d). 


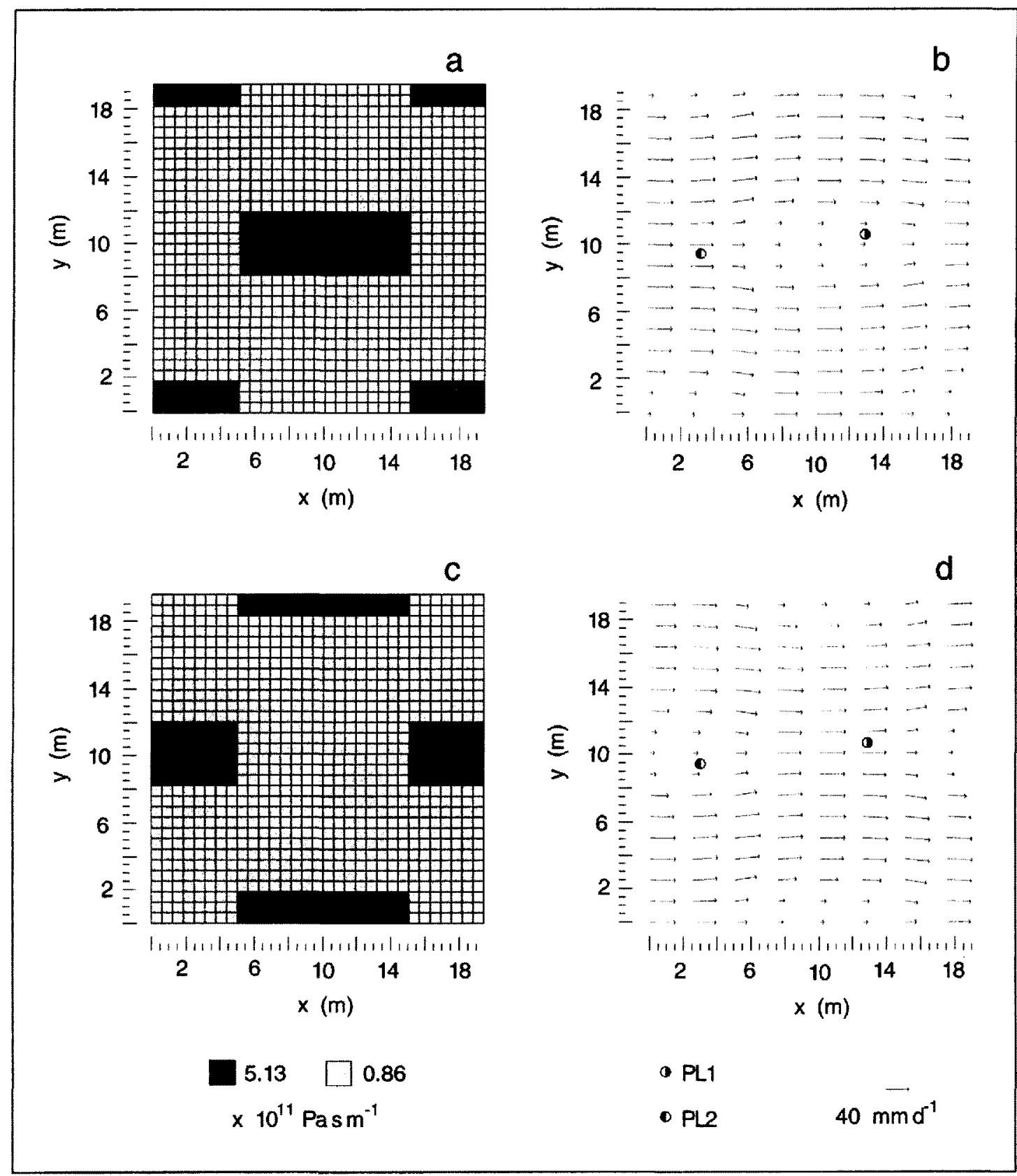

Fig. 5. Drag-coefficient surfaces, as defined on a $32 \times 32$ grid of area $A$, and calculated ice-flowe velocity fields immediately above the glacier bed. (a) High drag centred on gridpoint (17,17). (b) Divergent and slowed-down ice flow. (c) Low drag in the centre of area A. (d) Convergent and accelerated ice flow. The locations of two numerical ploughmeters (PLI and PL2) positioned at gridpoints $(7,16)$ and $(23,18)$ are also indicated.

Figurc $5 \mathrm{~b}$ and $\mathrm{d}$ show that, as the central region of $A$ alternates between being sticky and slippery, some of the flow vectors rotate back and forth and change their lengths. The change in length of a flow vector corresponds to a change in basal sliding velocity of ice at that point, whercas rotation indicates a reorientation of the ice-flow direction. For patchiness length scales substantially less than the ice thickness there is a ncgligiblc response at the glacier surface to such variations in the pattern of the basal sliding velocity (Balise and Raymond, 1985). If one accepts that variations in the force response of a ploughmeter indicate changes in the sliding velocity caused by temporal and spatial variations of basal resistance, it follows that for Trapridge Glacier the basal resistance is highly variable over distances of $O(10)$ and sub-daily time-scales. This variability is attributed to changes in the subglacial hydrological system, an interpretation that is strengthened by the findings of Murray and Clarke (1995) and Stone and Clarke (1996) who show that over short distances the subglacial water system is highly heterogeneous and that rapid pressure changes can occur at the bed. Because of the short timescale for creation and destruction of sticky spots, significant changes in glacier gcometry cannot develop and a quasistatic assumption is justified.

We now consider how ploughmeters might respond to the diurnal creation and destruction of sticky spots. In our further analysis, we imagine the consequence of positioning two ploughmeters (PL1 and PL2) at gridpoints $(7,16)$ and $(23,18)$ (Fig. 5). With the side lengths of area $A$ chosen to be $L_{x}=L_{y}=20 \mathrm{~m}$, the location of these gridpoints corresponds to a separation of the ploughmeters by approximately $10 \mathrm{~m}$, whilc the line joining the two points forms an angle of $\sim 7^{\circ}$ with the $x$ direction. This choice of ploughmetcr positioning is therefore consistent with the known properties of the field set-up (the insertion sites of ploughmeters 92PL02 and 92PL05 were $\sim 10 \mathrm{~m}$ apart, while the line joining the 
sites was at an angle of $\sim 8^{\circ}$ from the direction of glacier flow). With our assumption that the force response of a ploughmeter is linearly proportional to the basal sliding rate, we notc that the change in length of the flow vectors at the two gridpoints translates into a change in forces experienced by PL1 and PL2. In addition, the rotation of the flow vectors is equivalent to a rotation of the force angle about the ploughmeters.

Recalling our assumption of a water-pressure-dependent basal resistance to sliding, we computed the force and azimuth responses of PLl and PL2 (Fig. 6) for a varying basal drag that is based on the water-pressure record shown in Figure 2e. In our calculations, low subglacial water pressures correspond to high resistance in the centre of area $A$ and vice versa. The force responses shown in Figure $6 \mathrm{a}$ and $c$ are normalized with respect to the background basal sliding velocity $v_{\mathrm{b} x}^{0}\left(40 \mathrm{~mm} \mathrm{~d}^{-1}\right)$. The computed results (Fig. 6) display a striking similarity to the field data shown in Figure 2: the force records (Fig. $6 \mathrm{a}$ and c) indicate variations that are $180^{\circ}$ out-of-phase with each other, whilc the azimuth records (Fig. 6 b and d) show an in-phase rotation of the force angle by roughly $10^{\circ}$.

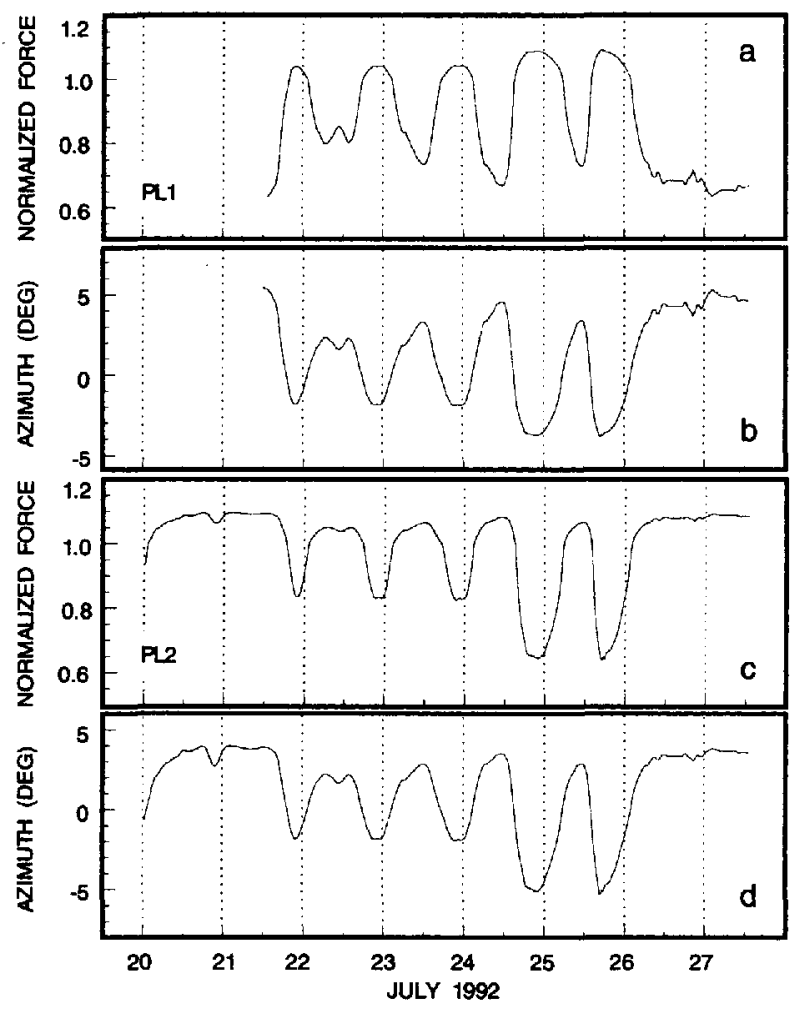

Fig. 6. Computed responses of two numerical ploughmeters (PL1 and PL2) positioned at gridpoints $(7,16)$ and $(23,18)$ for a varying basal drag that is based on the water-pressure record shozen in Figure 2e. (a) Synthetically generated force record for PL1. (b) Synthetically generated azimuth record for PLI. (c) Synthetically generated force record for PL2. (d) Synthetically generated azimuth record for PL2. Note the similarity io Figure $2 a-d$.

\section{CONCLUDING DISGUSSION}

Our model calculations for the flow of icc over a flat surface having variable resistance are based on the approximation that ice behaves as a linear viscous fluid. The purpose of the model is to demonstrate how local values of shear stress might vary with time and space. The non-lincarity of Glen's flow law would greatly complicate the model without contributing additional insight.

In our derivation of Equation (9), we neglected higherorder perturbation terms. This is an acceptablc approximation when perturbations of the drag coefficient are small compared to the background drag coefficient. Howcver, from Table 1 we see that the coefficients for background drag and perturbation drag have values that are of the same order of magnitude. Thus our model can be faulted for using a linear perturbation analysis to describe a situation where the neglected non-linear terms may be quite large. In this respect the present work shares a shortcoming common to all glaciological exploitations of linear sliding theory. Nevertheless, a more rigorous analysis which retained these non-linear terms should also attend to the other expedient assumptions of our model, namely, linear ice rheology and a highly simplified sliding law.

A possible incongruity of our model relates to the comparative stiffness of ice and subglacial material. Implicitly we assume that the bed is typically soft enough to allow ploughmeters to be dragged through it, yet locally stiff cnough to resist and deflect the flow of overlying ice. An alternative model, antithetical to ours, might also yield a consistent cxplanation of the ploughmeter records (Fig. 2). If, in comparison with bed material, ice was assumcd to bc essentially rigid, then the deformation response to patchy stickiness at the ice bed contact would be concentrated in the bed and there would be no deflection of the ice flow. Anomalous signals from the ploughmeters would then be taken as indications of sediment motion rather than ice motion. It might bc possiblc to develop an interpretation model that would, for a linear viscous till rheology, resemble the mirror image of that described in the present paper. We cannot discount this possibility, but have reasons to prefer the view that ice is deformable and responsive to local conccntrations of sliding resistance. Icequakes, numerous throughout the summer melt season, and deep englacial cracks, encountered during hot-water drilling, are clear evidence for the existence of large deviatoric stresses near the glacier bed. A uniformly weak substrate would be incapable of transmitting such stresses into the overlying ice. In a previous paper (Fischer and Clarke, 1994) our interpretation of ploughmeter records assumed a linear viscous till rheology, but this is clearly an oversimplification. Subglacial sediments tend to be highly heterogeneous and span a wide range of grain-sizes. This characteristic might result in scale-dependent rheological properties that could reconcile the conflicting requirements of soft-bed interactions with ploughmeters and hard-bed interactions over large sticky spots.

In conclusion, our observations and model calculations point to the existence of sticky spots beneath Trapridge Glacier. Although we have demonstrated consistency for only one example, it is conceivable that therc are sticky spots all across the bed of our main study region. These sites of cnhanced basal drag are ephemeral in nature because they are created and destroyed in response to fluctuations in subglacial water pressure. Therefore, it is unlikely that they support a large fraction of the driving stress for ice flow. Our previous result, that the deformational resistance of the sedimentary bed is of comparable magnitude to that required to balance the applied basal shear stress (Fischer and Clarke, 1994), strengthens our argument that sticky 
spots are probably not dominant in controlling the flow of Trapridge Glacier.

Our findings can be compared with results from other sites. Intcrpretation of data collected near the Upstream B camp (Alley, 1993) suggests that the lubricated regions of the bed support $>87 \%$ of the basal shear force. This leaves $<13 \%$ of the basal shear force to be supported on sticky spots, implying that sticky spots do not dominate the force balance in this region of Ice Stream B. However, a study by Echelmeyer and others (1994) suggests that care has to be taken in extrapolating localized basal conditions in the vicinity of Upstream B camp to the remainder of Ice Stream B. Flow-model calculations indicate that the margins play an important role in controlling ice-strcam motion, with marginal drag being equal to or greater than basal drag at some locations. These findings are strengthened by measurements of the marginal shear stress of Ice Stream G which imply that $63100 \%$ of the ice stream's support against the gravitational driving stress comes from the margins Jackson and Kamb, 1997). In contrast to our results, Whillans and others (1989) reported that Byrd Glacier, Antarctica, is held mainly by basal drag that is concentrated at a few sites separated by about $13 \mathrm{~km}$. Analysis of work done on Icc Stream C (Alley and others, 1994; Anandakrishnan and Alley, 1994) indicated that the base of the ice stream consists of a weak till interspersed with sticky spots of area on the order of $10^{2} \mathrm{~m}^{2}$ with a spatial density on the order of $10 \mathrm{~km}^{2}$. As a result of a reduced watcr lubrication, it is claimed that these sticky spots support almost all of the driving stress and account for the negligible flow of Ice Strcam C. Similarly, the basal-friction distribution derived from surface velocity data of Icc Stream E (MacAyeal and others, 1995) confirms the suggestion that basal shear stress of the ice stream is extremely low except in isolated sticky spots. These sticky spots where basal friction exceeds the area-averaged driving stress are inferred to be scattered irregularly across the subglacial regime and comprise approximately $15 \%$ of the icc-stream area.

\section{ACKNOWLEDGEMENTS}

We thank the Natural Sciences and Engincering Research Council of Canada for funding this study, and the University of British Columbia for providing postgraduate fellowship support. Our fieldwork was conducted in Kluanc National Park. We thank Parks Canada and the Government of the Yukon Territory for granting permission to carry out studies in the park. Advice and assistance during our field program were gratefully received from S. J. Marshall, T. Murray and B. S. Waddington. We further acknowledge C. F. Raymond, R. B. Alley and W. D. Harrison for valuable comments and criticisms.

\section{REFERENGES}

Alley, R. B. 1993. In search of ice-stream sticky spots. 7. Glaciol, 39(133), $\underline{447-454 .}$

Alley, R. B. 1996. Towards a hydrological model for computerized ice-sheet simulations. Hydrol. Processes, 10(4), 649-660.

Alley, R. B., S. Anandakrishnan, C. R. Bentley and N. Lord. 1994. A waterpiracy hypothesis for the stagnation of Ice Stream C, Antarctica. Ann. Claciol., 20, 187-194.

Anandakrishnan, S. and R. B. Alley. 1994. loe Stream C, Antarctica, sticky spots detected by microearthquake monitoring. Ann. Glacinl., 20, 183-186.

Anandakrishnan, S. and C. R. Bentley. 1993. Micro-earthquakes beneath Ice Streams B and $\mathrm{C}$, West Antarctica: observations and implications. 7. Glaciol., 39(133), 455-462.

Atre, S. R. and C. R. Bentley. 1993. Laterally varying basal conditions beneath Ice Streams B and C. West Antarctica. f. Glaciul., 39/133), 507-514.

Balise, M.J. and C. F. Raymond. 1985. Transfer of basal sliding variations to the surface of a linearly viscous glacier. F. Glaciol, 31 (109), 308-318.

Blake, E.W., L. H. Fischer and G. K. C. Clarke. 1994: Direct measurement of sliding at the glacier bed. 7. Glaciol., 40(136), 595-599.

Clarke, G. K. C. and E. W. Blake. 1991. Geometric and thermal colution of a surge-type glacier in its quiescent state: Trapridge Glacier, Yukon Territory, Canada, 1969 89. f. Glacid., 37(125), 158 - 169.

Echelmeyer, K. A., W. D. Harrison, C. Larsen and J. E. Mitchell. 1994. The role of the margins in the dynamics of an active ice stream. F. Glacinl, 40 $(136), 527-538$.

Fischer, L. H. and G. K. C. Clarke. 1994. Ploughing of subglacial sediment f. Glariol., 40 134$), 97-106$

Fischer, U. H. and G. K. C. Clarke. 1997. Clast collision frequency as an indicator of glacier sliding ratc. F. Glaciol, $\mathbf{4 3}(145,460-466$.

Hooke, R. LeB., B. Hanson, N. R. Iverson, P. Jansson and L. H. Fischer. 1997. Rheology of till beneath Storglaciären, Sweden. ‥ Glaciol., 43(143):172-179)

Iverson, N. R., B. Hanson, R. LeB. Hooke and P. Jansson. 1995. Flow mechanism ol glaciers on soft beds. Science, 267 (5194),80-81.

Jackson, M. and B. Kamb. 1997. The marginal shear stress of Ice Stream B, West Antarctica. .7. Glaciol., 43 $(145,415-426$.

Kamb, B. 197(). Sliding motion of glaciers: theory and obscrvation. Rev: Geophys Space Phys, 8(4), 673728

Machyeal, D. R. 1992. The basal stress distribution of Ice Stream E, Antarctica, inferred by control methods. F. Geophys. Res: 97 (B1), 595-603.

MacAyeal, I). R., R. A. Bindschadler and T. A. Scambos. 1995. Basal friction of Ice Stream E, West Antarctica. 7. Glaciol., 41 (138), 247-262.

Murray, T. and G. K. C. Clarke. 1995. Black-box modeling of the subglacia water system. J. Geophys. Res., $100(\mathrm{~B} 7), 10,231 \quad 10,245$.

Paterson, W. S. B. 1994. The physics of glaciers. Third edition. Oxford, etc., Elsevier Press, W. H., S. A. Trukolsky, W.T. Vecterling and B. P. Flannery. 1992 Numerical recipes in FORTRA A: the art of scientific computing. Second edition. Cambridge, Cambridge University Press.

Rooney, S. T., D. D. Blankenship, R. B. Alley and C. R. Bentley. 1987. Till bencath Icc Strcam B. 2. Structure and continuity. 7. Geophys. Res. 92 B9), 8913-8920.

Shabtaie, S., I. M. Whillans and C. R. Bentley. 1987. The morphology of Ice Streams A, B, and $\mathrm{C}$, West Antarctica, and thcir environs. J. Geophys. Res., 92(B9), 88658883.

Stone, D. B. and G. K. C. Clarke. 1996. In situ measurements of basal water quality and pressure as an indicator of the character of subglacial drainage systems. Hydrol. Processes, 10(4), 61.5-628.

Van der Veen, C.J. and I. M. Whillans. 1989. Force budget: II. Application to two-dimensional flow along Byrd Station Strain Network, Antarctica. 7 . Glaciol., 35(119), 61-67.

Whillans, I. M., Y. H. Chen, C. J. van der Vecn and T. J. Hughes. 1989. Force budget: III. Application to three-dimensional flow of Byrd Glacier; Antarctica. J. Glaciol., 35 (119), 68-80. 